\title{
ANÁLISE DA ATUAÇÃo DOS DOMÍNIOS POLÍTICAS PÚBLICAS E RECURSOS HUMANOS EM UM ECOSSISTEMA EMPREENDEDOR
}

\section{ANALYSIS OF THE PERFORMANCE OF PUBLIC POLICY AREAS AND HUMAN RESOURCES IN AN ENTREPRENEURSHIP ECOSYSTEM}

\author{
Luiz Antônio dos Santos Filho \\ PUC Minas \\ luiz.santoseng@hotmail.com
}

\section{Liliane de Oliveira Guimarães \\ PPGA-PUC Minas \\ lilianeog@pucminas.br}

Henrique Cordeiro Martins

Universidade Fumec

henrique.martins@fumec.br

Luciana Branco Penna

UNIFEMM - Centro Universitário de Sete Lagoas - MG e PUC Minas

luciana.penna@unifemm.edu.br

\begin{abstract}
Artigo foi indicado para fast track no congresso IFBAE (Instituto Franco-Brasileiro de
\end{abstract} Administração de Empresas)

\section{RESUMO}

O objetivo deste artigo é analisar a atuação do Consórcio Público para o Desenvolvimento do Alto Paraopeba - CODAP, em Minas Gerais e das instituições de ensino e pesquisa da região no sentido de estimular atividades que permitam a diversificação econômica. Como base teórica foi utilizada a literatura sobre ecossistema empreendedor. A metodologia foi de natureza qualitativa, a partir de análise documental e 10 entrevistas com atores do CODAP e das instituições de ensino e pesquisa. Para a organização dos dados utilizou-se o software Nvivo, tendo sido feita a análise de conteúdo para interpretação dos dados. Ao verificar as ações do CODAP e das instituições de ensino e pesquisa para desenvolvimento da região constatou-se que essas têm o potencial de desenvolver um ambiente de negócios favorável à criação de empresas e que esse ecossistema poderá contribuir para a diversificação da economia local, tornando a região menos dependente das atividades minerárias.

Palavras-chave: Ecossistema empreendedor. Domínio Políticas Públicas. Domínio Recursos Humanos. Desenvolvimento. 


\begin{abstract}
The objective of this article is to analyze the performance of the Public Consortium for the Development of Alto Paraopeba - CODAP in Minas Gerais and of the teaching and research institutions of the region in order to stimulate activities that allow economic diversification. The literature on the entrepreneurial ecosystem was used as the theoretical basis. The methodology was qualitative in nature, based on documental analysis and 10 interviews with CODAP actors and teaching and research institutions. For the organization of the data, the software Nvivo was used, and content analysis was performed for data interpretation. When verifying the actions of CODAP and the educational and research institutions for the development of the region, it was verified that these have the potential to develop a business environment conducive to the creation of companies and that this ecosystem could contribute to the diversification of the local economy, making the region less dependent on mining activities.
\end{abstract}

Keywords: Entrepreneurial ecosystem. Domain Public Policies. Domain Human Resources. Development.

\title{
1 INTRODUÇÃO
}

A atividade mineradora instalada em determinadas localidades tem ensejado muitas críticas, desde a questão ambiental até a sustentabilidade econômica deste tipo de atividade. Arias, Atienza e Cademartori (2014), por exemplo, apontam que, quando a atividade minerária domina o cenário econômico da região e entra em declínio, toda a região sucumbe simultaneamente. Uma alternativa que tem sido colocada por pesquisadores para amenizar os problemas decorrentes da dependência econômica é a evolução do que denominam de enclave minerário, para cluster. Ao se estimular o território para que evolua de um enclave para um polo minerário, pode-se perceber o desenvolvimento de outras atividades econômicas complementares e suplementares à atividade minerária o que, em caso de decadência ou exaustão, pode amenizar os problemas econômicos e sociais da região. Segundo Phelps (2008) e Cademartori (2009) o enclave de mineração leva ao desenvolvimento regional insustentável, enquanto a formação de um cluster, de acordo com Markusen (1996), Ramos (1998), Cruz e Teixeira (2010), gera um processo de desenvolvimento endógeno e diversificação do mix industrial que é benéfico para a região.

A alternativa para reversão do aprisionamento minerário encontra-se na maior articulação entre estado, universidade e setor produtivo em busca de novas possibilidades econômicas para região (RODRÍGUEZ, 1996; CARDOSO; FALETTO, 2000). Santos e Paula (2012) defendem que a integração entre Estado, instituições de ensino e pesquisa e o setor produtivo possibilita o desenvolvimento regional. Segundo os autores, essa integração e o desenvolvimento de esforços conjuntos proporcionam condições e motivação para as pessoas empreenderem.

A integração de diferentes atores em um território com o objetivo de promover condições propícias às atividades econômicas e melhoria do contexto social tem sido discutida na literatura a partir do conceito de ecossistemas empreendedores (GNYAWALI; FOGEL, 1994; BYGRAVE, 1998; ADNER, 2006; KENNEY; PATTON, 2006; OECD, 2009; ISENBERG, 2010, 2011; FOSTER et al., 2013; CARVALHO; VIANA; MANTOVANI, 2016; MINEIRO; MIRANDA; OTTOBONI; PASIN, 2016; BORISSENKO; BOSCHMA, 2017).

Para Isenberg (2011), um ecossistema empreendedor é formado a partir do alinhamento de diferentes instituições ou domínios, nas suas palavras, quais sejam: Políticas 
Públicas, Capital Financeiro, Cultura, Instituições de Suporte, Recursos Humanos e Mercados. $\mathrm{O}$ autor argumenta que o maior entrosamento entre esses domínios favorece iniciativas empreendedoras e que isso tem um efeito multiplicador, ou seja, outras empresas poderão ser fundadas com a finalidade de prover novos produtos e serviços, dando sequência a um círculo virtuoso e tornando assim a região mais dinâmica e competitiva.

Acredita-se que a economia de uma região pode ser bastante estimulada a partir das ações individuais dos domínios e do trabalho conjunto das instituições (ISENBERG, 2011). As universidades e centros tecnológicos, por exemplo, podem apoiar novos empreendimentos locais, fortalecendo o desenvolvimento do território (SANTOS; PAULA, 2012). Essa visão é também a de Teece (2007), pois para o autor, o apoio para geração ou a ampliação de negócios dentro de um ecossistema empreendedor pode ser feito a partir da atuação das universidades e centros tecnológicos.

É nessa discussão que esse artigo se insere. Como tem sido a atuação do poder público dos municípios constituintes do Consórcio Público para o Desenvolvimento do Alto Paraopeba - o CODAP e as ações das instituições federais de ensino e pesquisa instaladas no território para o fomento e fortalecimento de um ecossistema empreendedor no Alto Paraopeba? Nesse sentido, a pesquisa que embasou o trabalho teve por objetivo analisar como tem sido a atuação do CODAP, com sede em Conselheiro Lafaiete, Minas Gerais, e das instituições de ensino e pesquisa da região no sentido de estimular atividades produtivas que permitam a diversificação econômica.

O artigo foi estruturado da seguinte forma. Para além dessa introdução, discute-se, na seção 2, o referencial teórico utilizado como apoio no desenvolvimento do trabalho, finalizando com o modelo teórico elaborado para subsidiar a análise dos dados. A terceira seção apresenta a metodologia utilizada na pesquisa e, na seção 4, apresenta-se a descrição e análise dos dados obtidos. Por fim, as conclusões e considerações finais sobre a experiência de formação do Consórcio Público para o Desenvolvimento do Alto Paraopeba e sua articulação com as instituições de ensino e pesquisa da região.

\section{ECOSSISTEMAS EMPREENDEDORES}

$\mathrm{Na}$ literatura, ambientes de negócios são definidos por vários autores como ecossistemas empreendedores. Os principais estudos abordam o tema categorizando os elementos do ambiente empreendedor (GNYAWALI; FOGEL, 1994; KENNEY; PATTON, 2006; ISENBERG, 2010, 2011; FOSTER et al., 2013). Ecossistema empreendedor refere-se à articulação entre as intervenientes institucionais e individuais, de maneira a fomentar o espírito empresarial, a inovação e o crescimento das empresas (CARVALHO; VIANA; MANTOVANI, 2016). De acordo com Mineiro, Miranda, Ottoboni e Pasin, (2016), ecossistema de negócios pode ser entendido como uma comunidade econômica estruturada por organizações e indivíduos, incluindo fornecedores, fabricantes, concorrentes e outros grupos de interesse, numa dinâmica de interação entre os atores da rede. Ecossistema empreendedor é uma estrutura que é estimulada e se desenvolve quando ocorre o que Isenberg

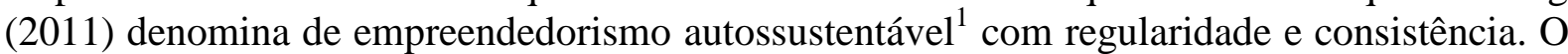
autor também salienta que a maneira mais rápida de criação do ciclo virtuoso de geração de novos negócios é a atuação direta no cultivo e desenvolvimento de um ecossistema geograficamente concentrado que seja propício ao sucesso do empreendedorismo local.

Numa perspectiva similar, Kenney e Patton (2006) defendem que a vantagem de uma região em relação a outra pode ser avaliada a partir da força das suas instituições. São instituições presentes e ativas em determinado contexto que configuram o ecossistema empreendedor. Essa configuração é definida pelos autores como estrutura social disposta ao empreendedorismo e à inovação. O diferencial de um ecossistema empreendedor é a 
possibilidade de criação de valor e crescimento das firmas locais a partir do estímulo às potencialidades endógenas. Adner (2006) reforça esse argumento ao escrever que uma empresa possui vantagens por estar inserida em um ambiente empreendedor, quando em contato com instituições de apoio e outras empresas. Isso pode lhe proporcionar criação de valor e crescimento, ressaltando que o potencial endógeno do território e a disposição à inovação são os aspectos que incentivam o crescimento e o desenvolvimento do ecossistema de negócios.

A partir dos estudos sobre ecossistemas empreendedores e seus elementos constituintes ou domínios Isenberg (2010), alguns modelos foram elaborados (GNYAWALI; FOGEL, 1994; ISENBERG, 2010, 2011; FOSTER et al., 2013). Representando o conjunto de elementos ambientais considerados como formadores da estrutura de um ecossistema empreendedor. A Figura 1 ilustra o modelo proposto por (ISENBERG, 2011).

Figura 1 - Domínios do ecossistema empreendedor proposto por Isenberg (2011).

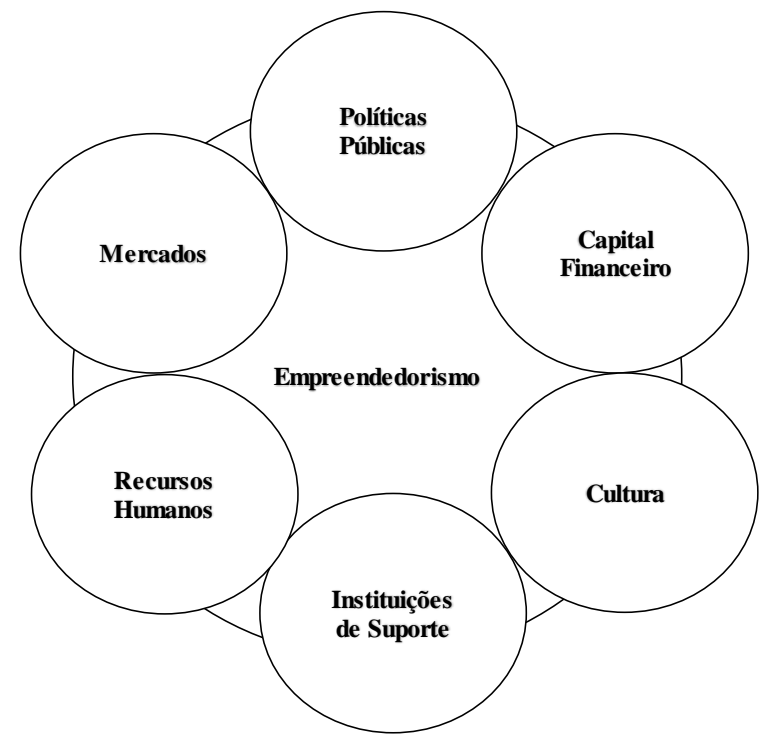

Fonte: Isenberg (2011).

Isenberg (2011) define que o domínio das Políticas públicas é constituído pelas dimensões liderança e governo. Essas dimensões contemplam elementos como legitimidade social, suporte inequívoco, apoio financeiro, estrutura regulatória, dentre outros. O papel governamental, por meio das políticas públicas, é considerado primordial para a formação do ecossistema empreendedor, pois acredita-se que através das políticas de incentivo é possível reduzir as barreiras burocráticas e facilitar iniciativas empreendedoras.

Da mesma forma, Gnyawali e Fogel (1994) destacam que os governos têm influência sobre os mecanismos de mercado e o poder de fazê-los funcionar de forma eficiente, eliminando possíveis condições que gerem imperfeições e rigidez administrativa. $\mathrm{O}$ poder público pode ajudar na criação de uma cultura empresarial regional, fomentando um ambiente de negócios que gere confiança para que as empresas possam assumir riscos e inovar. Da mesma forma que Isenberg (2011), Foster et al. (2013) afirmam em seu relatório para o World Economic Forum (WEF) que os empreendedores avaliam as políticas regulatórias governamentais como sendo simultaneamente aceleradoras e inibidoras do crescimento de empresas recém-criadas. Os autores argumentam que políticas públicas que reduzem as exigências burocráticas possibilitam que o mercado opere de forma livre, assim, consequentemente, os empreendedores enfrentam menos barreiras iniciais e podem vislumbrar maiores oportunidades de negócios. Da mesma forma, para Gnyawali e Fogel (1994) os empreendedores podem se sentir desencorajados para iniciar um novo negócio se 
tiverem que enfrentar muita regulamentação, se forem obrigados a se reportar a muitas instituições e se tiverem muito gasto de tempo e dinheiro no cumprimento de procedimentos burocráticos.

O domínio Capital financeiro é constituído pela dimensão capital financeiro. Nesta dimensão são encontrados os mecanismos de financiamento que atuam em prol do desenvolvimento dos empreendimentos, desde seu nascimento até sua maturação. Dentre as unidades listadas pelo autor neste domínio, observa-se a presença de elementos voltados ao apoio às pequenas empresas, como os programas de micro empréstimos, investidores anjos ${ }^{2}$, fundos de capital de risco para estágios iniciais, até alternativas de financiamento às grandes empresas como a existência de mercados de capitais bem desenvolvidos (ISENBERG, 2011). Gnyawali e Fogel (1994) ressaltam que empreendedores necessitam de assistência financeira para atender ao menos um dos três propósitos: diversificar ou difundir os riscos de uma startup, levantar capital inicial necessário para começar um novo negócio e também o financiamento do crescimento e da expansão das empresas existentes.

Isenberg (2011) identifica o domínio Cultura a partir de duas dimensões: histórias de sucesso e normas da sociedade. A primeira dimensão está relacionada à maneira com que os indivíduos interagem e articulam em seus grupos, como comportam frente a atividade empreendedora e como é feita a atribuição de valores diante do sucesso e do fracasso. Já a segunda dimensão, na perspectiva do autor, envolve as normas sociais que guiam a percepção dos indivíduos frente aos desafios de mercado, aos riscos e aos erros, a experimentação e a criatividade.

De forma semelhante a Isenberg (2011), Gnyawali e Fogel (1994) frisam que as pessoas têm o desejo de serem independentes a partir do empreendedorismo e assumindo riscos moderados. Da mesma forma que Gnyawali e Fogel (1994) fizeram em seu estudo, Foster e sua equipe no relatório WEF (2013) definiram alguns elementos que compõem as condições socioeconômicas de um ecossistema empreendedor, sendo eles a tolerância aos riscos e falhas, preferência por empreender e ter a própria empresa, histórias de sucesso empresarial como exemplos, cultura de pesquisa, imagens positivas do empreendedorismo, exaltação à inovação, universidades contribuindo para o empreendedorismo e atuando na geração de ideias para novos negócios. As condições socioeconômicas carregam traços sociais e são indicadores da atitude da sociedade frente ao empreendedorismo (GNYAWALI; FOGEL, 1994; ISENBERG, 2011; FOSTER et al., 2013).

O domínio Instituições de suporte é definido por Isenberg (2011) a partir de três dimensões: infraestrutura, profissões de apoio e instituições não governamentais. A dimensão infraestrutura se refere a infraestrutura local como telecomunicações, energia, transportes e logística. As profissões de apoio representam a dimensão relacionada aos profissionais que dão suporte aos empreendedores, como advogados, contadores, banqueiros e os serviços de orientação técnica em setores específicos. Já a dimensão instituições não governamentais é caracterizada como um conjunto de instituições formadas pela sociedade civil como associações de apoio aos empreendedores. Segundo o autor o funcionamento desses elementos facilita a ocorrência da atividade empreendedora. Foster et al. (2013) fortalecem o conceito de domínio Instituições de suporte de Isenberg (2011) ao identificar como elementos participantes de um ecossistema empreendedor os consultores de negócios, os serviços profissionais, as incubadoras e aceleradoras de empresas e a presença de uma rede densa de empreendedores.

O domínio Recursos humanos apresentado no estudo de Isenberg (2011) é dividido nas dimensões mão de obra, compreendendo elementos como mão de obra treinada e não treinada, e em instituições educacionais que são definidas pela existência dos elementos universidades, escolas técnicas e programas de treinamentos específicos na área do empreendedorismo. De forma resumida, esse domínio contempla os empreendedores e a mão 
de obra geral, sendo ambos qualificados por meio da educação. Gnyawali e Fogel (1994) relacionam esse domínio às competências empresariais. Para os autores essas competências estão relacionadas a educação técnica e vocacional presente no ambiente, a educação voltada para a gestão e negócios, aos programas de treinamento para o empreendedorismo, aos programas técnicos e ao acesso às informações. Já Foster et al. (2013) definiram a presença de talentos em gestão, talentos técnicos, a experiência em empresas empreendedoras, disponibilidade de fornecedores, acesso a força de trabalho estrangeira, grandes universidades fornecendo capital humano para as novas empresas, disponibilidade de força de trabalho qualificado com educação básica e universitária e treinamentos específicos de empreendedorismo, como sendo elementos de habilidades empreendedoras e de gestão presentes no domínio capital humano.

Isenberg (2011) conceitua o domínio Mercados pelas dimensões clientes iniciais e redes. Os clientes iniciais são compreendidos como os grupos de teste, incluindo as análises preliminares dos produtos e serviços ofertados, bem como os canais de distribuição prontos para a divulgação dos novos produtos, distribuindo-os através de uma rede de contatos nacional e internacional. Já as redes são compreendidas como sendo a presença de empresas multinacionais, redes de empreendedores e outras redes interligadas a novos negócios. Foster et al. (2013) sugerem que um pequeno conjunto de empresas atuando em rede influenciam as dinâmicas regionais de empreendedorismo e são determinantes na fase inicial de desenvolvimento de uma nova empresa do mesmo setor. Da mesma forma, também as grandes corporações que compõem um ecossistema empreendedor têm o papel de impulsionar o crescimento de novas empresas em fase inicial. Mas essa relação pode, em algumas situações, não ser harmoniosa, gerando conflitos que desestimulam o crescimento dos novos negócios, reduzindo fontes de receitas e gerando perda de capital humano (FOSTER et al., 2013).

Isenberg (2011) defende que para promover o desenvolvimento do empreendedorismo, é desejável que todos os domínios do ecossistema de negócios apresentados sejam organizados e atuantes, contudo o autor ressalta que não é necessário se preocupar em intervir e mudar tudo em uma escala completa de uma só vez. Na avaliação do autor, alteração em um dos domínios ou em alguns deles já se traduz em melhoria nas condições econômicas do território.

No contexto diversificado de realidades econômicas, a Organisation for Economic Cooperation and Development (OECD) desencadeou um movimento de mapeamento das diferentes experiências de desenvolvimento a partir do empreendedorismo. O objetivo central da OECD é assessorar líderes políticos por meio de uma base de dados internacional comparativa de diferentes cenários econômicos com indicadores que representem os elementos determinantes do empreendedorismo de cada realidade (ARRUDA; NOGUEIRA; COSTA, 2013). A OECD identifica e classifica três diferentes etapas interligadas e que fazem parte da avaliação e formulação das políticas de estímulo ao empreendedorismo: determinantes; desempenho empresarial; impacto. A primeira etapa do modelo refere-se às diferentes determinantes que as políticas públicas podem manipular de forma a estimular a economia local. A segunda etapa mensura, através de indicadores, o desempenho empresarial, ou a quantidade e os tipos de empreendedorismo que ocorrem na região a partir da manipulação das determinantes. A etapa final é o resultado do aumento de taxas de empreendedorismo, como o crescimento econômico, a criação de empregos ou a redução da pobreza.

A Figura 2 apresenta por categoria as etapas elaboradas pela OECD. 
Figura 2 - Principais categorias para indicadores do empreendedorismo OECD (2009)

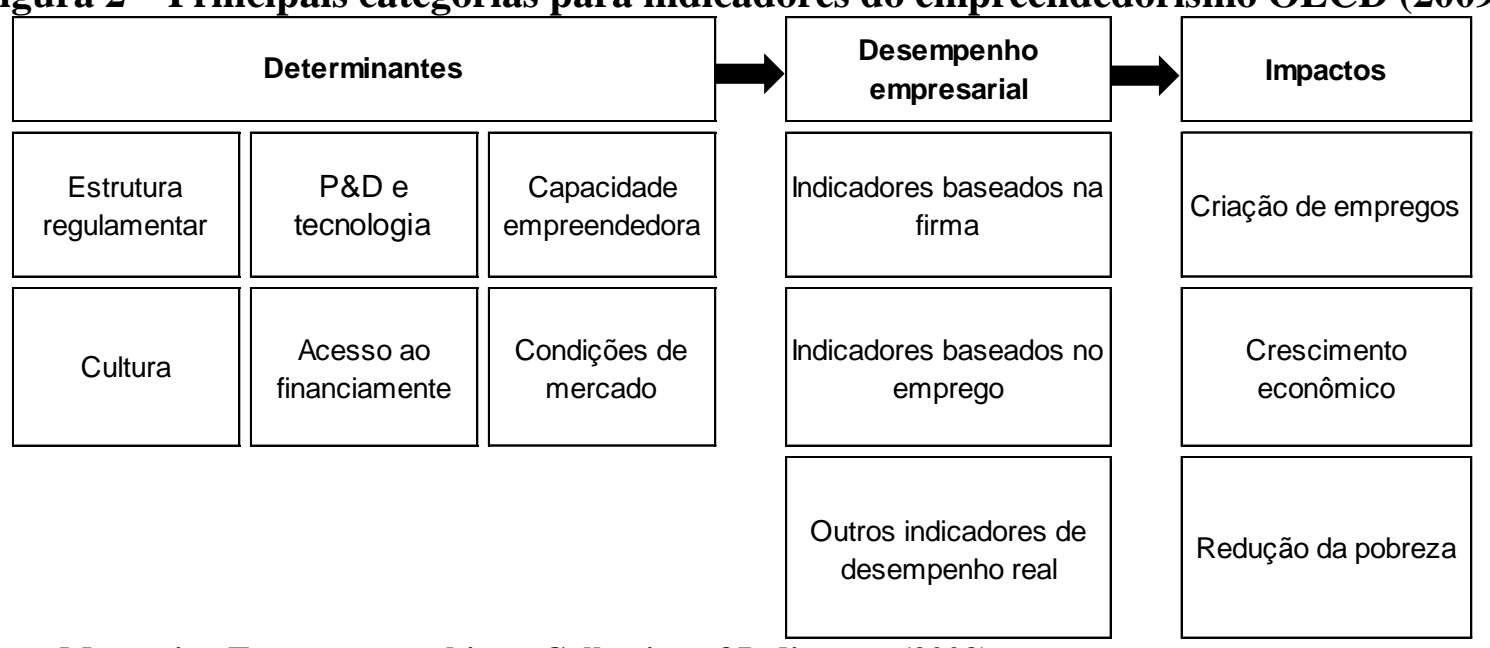

Fonte: Measuring Entrepreneurship: a Collection of Indicators (2009).

\subsection{Modelo teórico para análise dos dados}

O modelo teórico que embasou a pesquisa do artigo partiu, prioritariamente, da proposta de ecossistema elaborada pela OECD (2009), mas realizando um recorte, ou seja, priorizando a análise de dois pilares, ou seja, as ações do poder público e das instituições de ensino e pesquisa na geração de inovação e capacidade empreendedora para região. A escolha por analisar determinadas etapas é condizente com o pressuposto de Isenberg (2011) de que o ideal é que todos domínios de um ecossistema empreendedor sejam fortalecidos para o sucesso do empreendedorismo regional, mas não necessariamente de uma só vez.

O modelo foi elaborado contemplando ações do Poder Público / Políticas Públicas articuladas com ações das Instituições de Ensino e Pesquisa / Recursos Humanos e suas influências na geração de potencial empreendedor e inovação para o desenvolvimento de um ecossistema empreendedor no território do Alto Paraopeba. No domínio Políticas Públicas / Poder Público são analisadas, as instituições de apoio, as estratégias empreendedoras, o apoio financeiro bem como a estrutura de regulação, conforme consta no modelo de (ISENBERG, 2011). No domínio Recursos Humanos / Instituições de Ensino e Pesquisa é analisada a contribuição destas entidades na formação de indivíduos com competências para o empreendedorismo e as pesquisas desenvolvidas na região que possam contribuir para formação de novos negócios e o fortalecimento dos já existentes. 
Figura 3 - Modelo teórico para análise dos dados

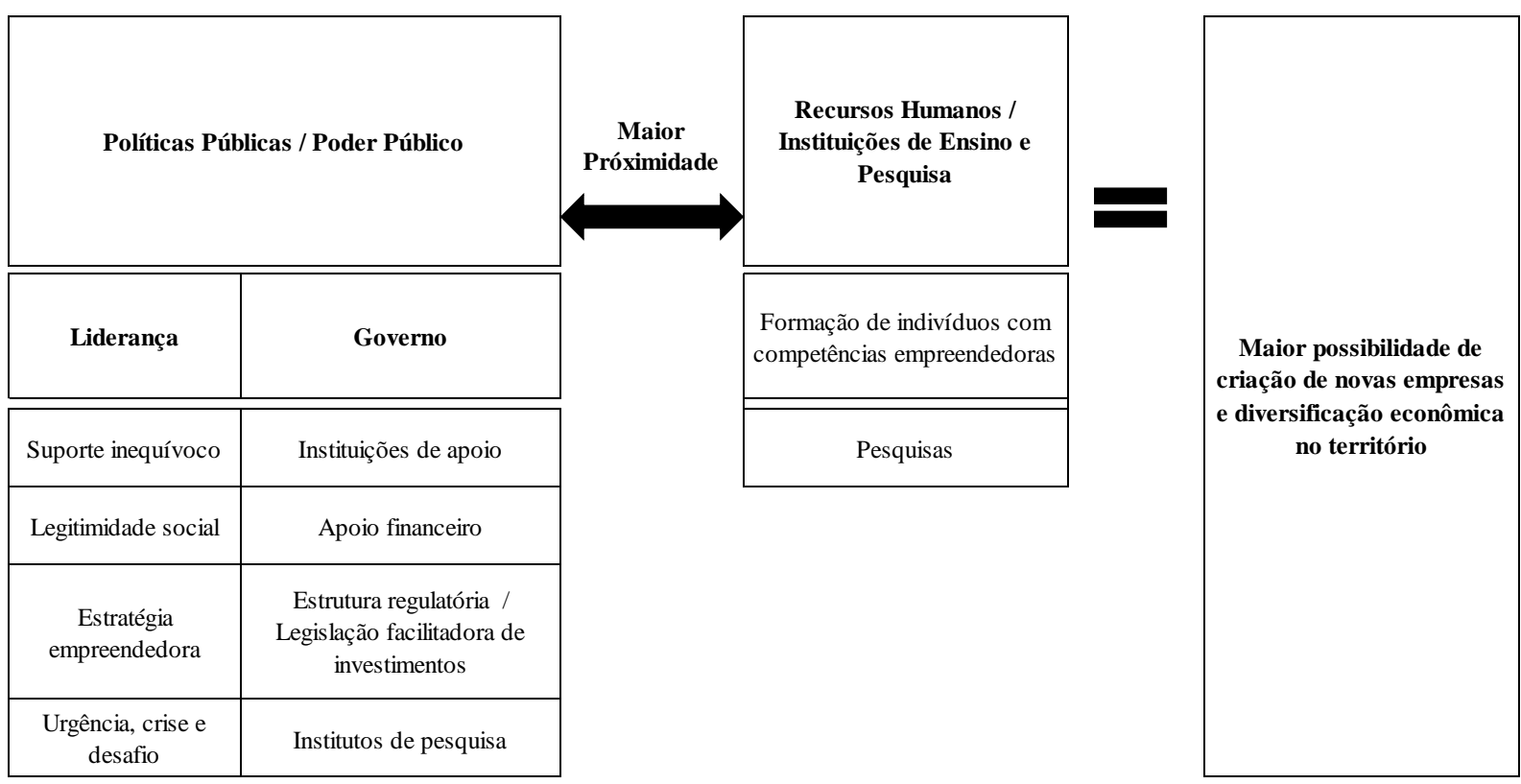

Fonte: Elaborado pelos autores com dados extraídos do referencial teórico, predominantemente OECD (2009) e Isenberg (2011).

O modelo teórico elaborado com base em Gnyawali e Fogel (1994), OECD (2009), Isenberg (2011) e Foster et al. (2013) pressupõe que quanto mais estreita for a aproximação e integração entre ações do poder público com as instituições de ensino e pesquisa, mais o ecossistema empreendedor na região estará sendo, mesmo que parcialmente, fortalecido, com probabilidade maior de que novas empresas sejam criadas e, consequentemente, gerando maior riqueza econômica para a região.

\section{METODOLOGIA}

Para realização de uma análise coerente com o contexto do processo de desenvolvimento regional articulado na Região do Alto Paraopeba pelo consórcio público CODAP, optou-se pelo estudo de caso de natureza qualitativa para a investigação. Segundo Minayo, Deslandes, Cruz e Gomes (2002), a pesquisa qualitativa abrange os significados, sentidos, motivos, aspirações, crenças, valores e atitudes, o que permite um conhecimento mais profundo dos processos, eventos e fenômenos analisados. Para o desenvolvimento da pesquisa foi utilizado o método de estudo de caso único (YIN, 2005).

A operacionalização da coleta de dados para a pesquisa ocorreu em três etapas entre o período de março de 2016 a outubro de 2017. Foram realizados levantamento documental e entrevistas semiestruturadas. As entrevistas foram realizadas com os atores participantes do CODAP e pertencentes às instituições de ensino e pesquisa. Um critério de escolha dos entrevistados foi o envolvimento direto dos mesmos com questões de desenvolvimento do território em destaque. A pesquisa documental foi realizada com base na documentação disponibilizada pelos profissionais do CODAP, como atas de reunião e outros materiais relativos às decisões sobre a governança do território. Também foram considerados documentos referentes às ações constantes no Plano de Desenvolvimento Regional para o Alto Paraopeba - CODAP, como os elaborados pelo Centro de Desenvolvimento e Planejamento Regional - CEDEPLAR, por solicitação do CODAP. 
O volume de dados gerado pelas técnicas aplicadas na pesquisa foi organizado de forma eficiente, possibilitando fácil acesso as suas informações no decorrer do estudo. Para tal otimização o software Nvivo versão 10 foi utilizado. Após a categorização dos dados, foram expostas as categorias que estavam presentes nas entrevistas e nos documentos, bem como a frequência dessa presença. A análise de conteúdo proporcionou uma leitura consistente e diversificada dos dados coletados, permitindo uma redução das incertezas relacionadas aos mesmos.

As informações levantadas na pesquisa foram organizadas por categorias definidas com base no referencial teórico. No momento da organização dos dados foi detectada a necessidade de definir subcategorias que por sua vez alimentaram as categorias definidas a partir do modelo teórico de análise da pesquisa, enriquecendo a análise dos dados. No quadro 1 , são apresentadas as categorias com as suas respectivas subcategorias.

\section{Quadro 1 - Organização no Nvivo das Categorias e Subcategorias}

\begin{tabular}{|c|c|c|}
\hline Categorias & & gorias \\
\hline \multirow{3}{*}{$\begin{array}{c}\text { Políticas Públicas / Poder } \\
\text { Público }\end{array}$} & *Contexto do território & $\begin{array}{l}\text {-Contexto econômico histórico e } \\
\text { atual do território }\end{array}$ \\
\hline & *Liderança & $\begin{array}{l}\text { • Suporte inequívoco } \\
\text { •Legitimidade social } \\
\text { •Estratégia empreendedora } \\
\text {-Urgência, crise e desafio }\end{array}$ \\
\hline & 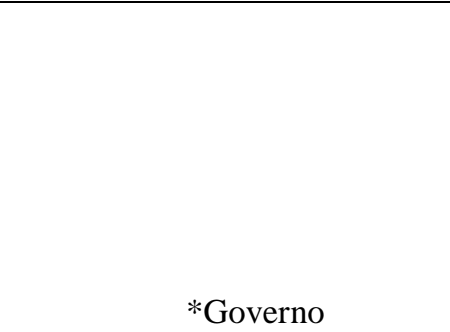 & $\begin{array}{l}\text {-Instituições de apoio } \\
\text { - Apoio financeiro } \\
\text { •Estrutura regulatória / Legislação } \\
\text { facilitadora de investimentos } \\
\text { - Institutos de pesquisa }\end{array}$ \\
\hline \multirow{2}{*}{$\begin{array}{c}\text { Recursos Humanos / Instituições } \\
\text { de Ensino e Pesquisa }\end{array}$} & \multicolumn{2}{|c|}{ *Formação de indivíduos com competências empreendedoras } \\
\hline & \multicolumn{2}{|l|}{ *Pesquisas } \\
\hline
\end{tabular}

Fonte: Elaborado pelos autores a partir do modelo teórico elaborado e dos dados coletados na pesquisa.

Os dados oriundos das entrevistas semiestruturadas e do levantamento documental foram analisados a partir da análise de conteúdo.

O quadro 2 apresenta os atores entrevistados e as funções exercidas nas organizações, porém preservando seus nomes. Conforme a tabela demonstra, foram entrevistados cinco representantes do CODAP, quatro dos IFMG(s) da região e o presidente do Instituto Geopark Quadrilátero Ferrífero, profissional que participou, desde o início, da formação do CODAP. 
Quadro 2 - Lista de entrevistados na pesquisa

\begin{tabular}{|c|c|c|}
\hline \multicolumn{3}{|c|}{ Lista de entrevistados } \\
\hline Instituição & Posição & Entrevistado \\
\hline CODAP / SEBRAE - MG & $\begin{array}{l}\text { Ex-prefeito de Congonhas e } \\
\text { Presidente CODAP }\end{array}$ & AP00 \\
\hline CODAP & $\begin{array}{l}\text { Coordenadora do Centro de } \\
\text { Referência e Capacitação para } \\
\text { Sustentabilidade Alto Paraopeba } \\
\text { (CESUP) }\end{array}$ & AP01 \\
\hline CODAP & Diretora Financeira & AP02 \\
\hline CODAP & Controlador Interno & AP03 \\
\hline CODAP & Secretário Executivo & AP04 \\
\hline UFSJ & $\begin{array}{l}\text { Professor do Departamento de } \\
\text { Ciências Econômicas }\end{array}$ & AP05 \\
\hline IFMG - Conselheiro Lafaiete & Professor e Diretor de Pesquisa & AP06 \\
\hline IFMG - Ouro Branco & $\begin{array}{l}\text { Professor e Coordenador de } \\
\text { Relações Empresariais }\end{array}$ & AP07 \\
\hline IFMG - Congonhas & Professor e Diretor de Pesquisa & AP08 \\
\hline $\begin{array}{l}\text { Polo de Excelência Mineral } \\
\text { Metalúrgico - GEOPARK }\end{array}$ & $\begin{array}{l}\text { Presidente do GEOPARK - } \\
\text { Quadrilátero Ferrífero }\end{array}$ & AP09 \\
\hline & Total & 10 Entrevistas \\
\hline
\end{tabular}

Fonte: Elaborado pelos autores a partir de dados coletados na pesquisa.

\section{RESULTADOS}

\subsection{O Consórcio Público para o Desenvolvimento do Alto Paraopeba - CODAP}

A região do Alto Paraopeba está localizada na Mesorregião de Belo Horizonte, estado de Minas Gerais e vem, desde de 2003, desenvolvendo ações no sentido de ampliar as atividades econômicas da região e reduzir a dependência econômica da atividade minerária (CEDEPLAR, 2010). Para isso, foi constituído em 2006, o Consórcio Público para o Desenvolvimento do Alto Paraopeba - CODAP - primeiro consórcio público entre municípios do Brasil com o objetivo de fomentar o desenvolvimento regional. Os municípios de Belo Vale, Congonhas, Conselheiro Lafaiete, Entre Rios de Minas, Jeceaba, Ouro Branco e São Brás do Suaçuí compuseram a formação inicial do CODAP. Em 2017 a composição do CODAP havia sofrido redução no número de municípios participantes, tendo o município de Belo Vale se desassociado do consórcio. A criação do consórcio e sua atuação como estratégia de desenvolvimento territorial teve como referência a experiência francesa da região de Nord-Pas-de-Calais. Essa região da França, em virtude de perda de competitividade da sua principal atividade econômica entre 1757 e 1990 - extração do carvão - (mudança de fontes energéticas, problemas ambientais decorrentes da atividade minerária, dentre outros), 
quando a última mina teve suas atividades encerradas, desenvolveu um plano para reconversão do território, ou seja, foram elaboradas e implementadas uma série de ações que tiveram por objetivo alterar a dinâmica econômica e social no território (REVISTA CODAP, 2010).

Inicialmente, a formação do CODAP estabeleceu, entre seus objetivos, trabalhar para impedir um crescimento desordenado da região, na medida em que a predominância da atividade minerária ocasiona grande fluxo de mão de obra e, por conseguinte, necessidade de habitação, serviços de educação, saúde, lazer (BARBIERI et al., 2010). A expectativa era que a formação do consórcio de municípios permitisse o planejamento territorial para minimizar impactos dos investimentos privados e promover a gestão associada de serviços públicos, para que houvesse melhor alocação de recursos e facilitar a integração e o desenvolvimento regional. Um exemplo dessas ações foi o Plano de Desenvolvimento Regional para o Alto Paraopeba, que teve como objetivo principal orientar, articular e otimizar as políticas, programas e intervenções públicas e privadas, de modo que se tentasse integração em todas as esferas de governo, visando o desenvolvimento regional (REVISTA CODAP, 2010).

Especificamente para discutir e elaborar projetos de desenvolvimento econômico para região, o CODAP criou, em 2014, o Conselho Estratégico de Desenvolvimento Econômico do Alto Paraopeba (CEDECAP). O CEDECAP, por meio das reuniões para discussão sobre o plano de desenvolvimento para a região do Alto Paraopeba definiu como prioridade de esforços e investimentos públicos e, de certa forma, desatrelados da atividade minerária, quatro eixos: o desenvolvimento da logística, da agricultura familiar, do turismo e do desenvolvimento tecnológico (Atas de reunião entre representantes do CEDECAP e das cidades pertencentes ao consórcio, 01/2015, 05/2015).

No que diz respeito ao eixo do desenvolvimento tecnológico, a ideia foi estimular a instalação de universidades e institutos tecnológicos na região, acreditando que esses poderiam prover de pessoal capacitado para atividades empreendedoras e, ao mesmo tempo, fomentar a criação de negócios. Atualmente, a região do Alto Paraopeba possui duas universidades federais, a Universidade Federal de São João Del-Dei (UFSJ) - Campus Alto Paraopeba, instalado em 2007, e a Universidade Federal de Minas Gerais (UFMG) - Polo Conselheiro Lafaiete. Possui também três institutos tecnológicos, sendo eles, o Instituto Federal de Educação, Ciência e Tecnologia de Minas Gerais (IFMG) - Campus Conselheiro Lafaiete, Campus Congonhas e Campus Ouro Branco (Lei $\left.n^{\circ} 11.892,2008\right)^{3}$. A Lei ${ }^{\circ} 11.892$, de 29 de dezembro de 2008 constituiu os novos Institutos Federais de Educação, Ciência e Tecnologia.

A instalação dessas instituições de ensino e pesquisa, com exceção do campus da UFMG - Polo Conselheiro Lafaiete no território, foram frutos da articulação do poder público local, por meio do CODAP, junto ao governo federal. O resultado desse esforço político permitiu a instalação de Institutos Tecnológicos nos três municípios âncoras da região Conselheiro Lafaiete, Ouro Branco e Congonhas - o que não é usual considerando a pouco distância entre eles.

Conforme definido por OECD (2009) e Isenberg (2011) e seguindo o modelo proposto no referencial teórico dessa pesquisa, o domínio Políticas Públicas / Poder Público é composto pelas dimensões Liderança e Governo. Na visão dos formuladores de modelos de ecossistemas empreendedores, a presença dessas dimensões na gestão pública vai contribuir para a promoção de um ambiente empreendedor forte no território.

Para entender o papel de liderança do CODAP na região do Alto Paraopeba foram analisados o suporte que o mesmo oferece no sentido de promover o desenvolvimento regional, sua legitimidade junto à comunidade local e identificadas suas estratégias empreendedoras bem como o seu senso de urgência, crise e desafio. Esses elementos se interpenetram quando se analisa a atuação do CODAP na região do Alto Paraopeba. Com 
relação ao elemento Suporte, para os entrevistados o CODAP é visto como tendo o papel de facilitar as relações entre poder público, instituições de ensino e iniciativa privada. Inicialmente, o CODAP buscou atuar como um mecanismo de governança nas relações entre as prefeituras dos municípios do Alto Paraopeba. O objetivo era otimizar o uso dos recursos municipais, planejar, de maneira conjunta, estratégias de desenvolvimento, promovendo equilíbrio político e financeiro dos diferentes municípios.

Para se discutir o elemento Legitimidade Social na dimensão Políticas Públicas do modelo teórico, há que se salientar novamente que o CODAP foi o primeiro consórcio público de desenvolvimento no Brasil, sendo que em um determinado momento, a Secretaria de Desenvolvimento Regional e de Políticas Urbanas (SEDRU) do Estado, tomou o CODAP como uma referência para disseminar a lógica de consórcios públicos no Estado.

A iniciativa de criação do CODAP foi pioneira, não no sentido de uma associação de municípios de maneira consorciada, pois antes do CODAP já existiam consórcios privados, mas as possibilidades de um consórcio público são muito maiores em relação ao modelo anterior de consórcio privado. Os consórcios de municípios anteriores eram uma associação privada, e esse modelo de associação tem uma série de limitadores que os impedem de prover alguns serviços públicos, o que não acontece com um consórcio público. Para os entrevistados, o consórcio público tem a legitimidade para assumir o papel público das prefeituras no raio de sua atuação.

O CODAP, com o objetivo de aproveitar as oportunidades existentes no ambiente do Alto Paraopeba proporcionadas pelas atividades da mineração e siderurgia e sem esquecer as potencialidades endógenas da região, traçou algumas Estratégias Empreendedoras - um dos elementos da dimensão liderança - para impulsionar a diversificação econômica do território, considerando, inclusive, um futuro sem mineração. Ao buscar desenvolver formas de fomentar a criação de novos negócios que atendam a necessidade de diversificação da economia do Alto Paraopeba para frentes além da mineração e siderurgia, as ações do CODAP se relacionam com elemento Urgência, Crise e Desafio proposto por Isenberg (2011) no Domínio Políticas Públicas de seu modelo de ecossistema empreendedor. As crises vividas periodicamente por este setor e até mesmo a provável saída dessas empresas da região com a exaustão do minério podem trazer consequências maléficas para a economia local. Já que o empreendedorismo favorece a inovação e criação de novas empresas, gerando assim crescimento do território (REIS; SIMÕES; GREATTI; PIZZI, 2006), o planejamento e a reflexão sobre novas oportunidades econômicas geradas pela atuação do CODAP representam ações que podem ser classificadas como urgentes, desafiadoras e de antecipação de crise.

De acordo com Etzkowitz (2003), Isenberg (2011) e Santos e Paula (2012) o papel do governo é fundamental para criação e consolidação de um ecossistema empreendedor. Assim, foram analisadas as ações do CODAP que possam indicar esforços no sentido de promover o empreendedorismo na região e a diversificação das atividades econômicas. Na verdade, a criação do consórcio público pode ser analisada de duas formas. A primeira como uma política pública para governança do território com vistas à promoção do seu desenvolvimento de maneira ampla. A segunda, como instituição de apoio às atividades empreendedoras. $\mathrm{Ou}$ seja, o CODAP pode ser entendido como a corporificação da dimensão Governo no Alto Paraopeba e como um dos elementos desta dimensão.

A análise da dimensão Governo foi feita a partir dos elementos instituições de apoio, apoio financeiro, estrutura regulatória e legislação facilitadora de investimentos e institutos de pesquisa. Esses elementos se interpenetram quando se analisa a atuação do CODAP na região do Alto Paraopeba. Segundo Camilotti (2001) e Isenberg (2011) faz parte do papel do poder público articular instituições que apoiem o empreendedorismo em um ecossistema empreendedor. As ações governamentais em todos níveis, municipal, estadual e federal são consideradas fundamentais para o crescimento econômico de um território. A análise do 
contexto de desenvolvimento do Alto Paraopeba indica que o consórcio CODAP representa uma das principais Instituições de Apoio ao empreendedorismo no território, já que vários dos seus esforços objetivam promover novos negócios e a diversificação econômica na região. Na pesquisa, ficou constatado que o poder público no referido território não fornece o apoio financeiro, a partir de concessão de crédito, aos empreendedores locais. No entanto, apoio financeiro pode ocorrer a partir de financiamento dos projetos elaborados pelo CODAP que visem desenvolver novas atividades econômicas na região.

Pode-se afirmar que o CODAP tem trabalhado no sentido de aperfeiçoar a estrutura regulatória para incentivar um ambiente de oportunidades de negócios que permita a criação e o fortalecimento de empresas locais, o que vai ao encontro do proposto por Isenberg (2011) Estrutura Regulatória e Legislação Facilitadora de Investimentos no Domínio Políticas Públicas de um ecossistema empreendedor.

O CODAP, por reconhecer a importância da existência de profissionais qualificados e com competências empreendedoras para fortalecimento do ecossistema empreendedor, estando de acordo com a proposição de Pinto, Fernandez-Esquinas e Uyarra (2015) em que o conhecimento é elemento chave para o desenvolvimento regional, buscou articular, junto ao governo Federal, a instalação dos Institutos Tecnológicos de Educação, Ciência e Tecnologia de Minas Gerais nas cidades de Conselheiro Lafaiete, Congonhas e Ouro Branco, além da instalação do Campus Alto Paraopeba da Universidade Federal de São João Del-Rey, também localizada no município de Ouro Branco. Esse esforço do consórcio para instalar instituições de ensino e pesquisa na região é coerente com o elemento Institutos de pesquisa mencionado por Isenberg (2011) no Domínio Políticas Públicas para formação e consolidação de um ecossistema empreendedor.

O quadro 3 sintetiza, a partir da percepção dos entrevistados, a indicação de presença dos elementos que compõe o Domínio Políticas Públicas proposto por Isenberg (2011) no ecossistema empreendedor do Alto Paraopeba. 
Quadro 3 - Indicador de presença dos elementos que compõe o Domínio Políticas Públicas no Alto Paraopeba

\begin{tabular}{|c|c|c|c|}
\hline \multicolumn{4}{|c|}{ Políticas Públicas / Poder Público } \\
\hline \multicolumn{4}{|c|}{ Liderança (Dimensão) } \\
\hline Elemento & Presente & $\begin{array}{c}\text { Parcialmente } \\
\text { Presente }\end{array}$ & Não presente \\
\hline Suporte inequívoco & $\mathrm{x}$ & & \\
\hline Legitimidade social & & $\mathrm{x}$ & \\
\hline Estratégia empreendedora & $\mathrm{x}$ & & \\
\hline Urgência, crise e desafio & $\mathrm{x}$ & & \\
\hline \multicolumn{4}{|c|}{ Governo (Dimensão) } \\
\hline Elemento & Presente & $\begin{array}{c}\text { Parcialmente } \\
\text { Presente }\end{array}$ & Não presente \\
\hline Instituições de apoio & & $\mathrm{x}$ & \\
\hline Apoio financeiro & & & $\mathrm{x}$ \\
\hline $\begin{array}{c}\text { Estrutura regulatória / } \\
\text { Legislação facilitadora de investimentos }\end{array}$ & $\mathrm{x}$ & & \\
\hline Institutos de pesquisa & $\mathrm{x}$ & & \\
\hline
\end{tabular}

Fonte: Elaborado pelos autores com dados extraídos de entrevistas e análise documental.

\subsection{Recursos Humanos / Instituições de Ensino e Pesquisa}

Em relação ao fortalecimento e a diversificação da economia local acredita-se que a estratégia das instituições de ensino e pesquisas da região é sustentada no tripé ensino, pesquisa e extensão. O pilar ensino objetiva conscientizar e desenvolver nos alunos o desejo de ser empreendedor, de perceberem que as possibilidades de carreira profissional não estão apenas nas oportunidades de serem empregados. No pilar das pesquisas, o objetivo é compreender o perfil do empresário local, as demandas e necessidades da região e as possibilidades de inovação e empreendedorismo presentes no ambiente. No que se refere aos projetos de extensão, o objetivo é realizar projetos com possibilidades de geração de riqueza para todos os membros da sociedade local.

Para o fomento de um ecossistema empreendedor é preciso haver uma relação de proximidade entre o Poder Público e as instituições de pesquisa (GNYAWALI; FOGEL, 1994; ETZKOWITZ, 2003; OECD, 2009; ISENBERG, 2011; SANTOS; PAULA, 2012; FOSTER et al., 2013). Por meio de pesquisas é possível descobrir oportunidades para o 
empreendedorismo ou desenvolver possibilidades para a criação de novos negócios. As pesquisas desenvolvidas nas instituições de ensino e pesquisa federais com o apoio do CODAP caracterizam-se em dois grupos. O primeiro grupo privilegia questões relacionadas à sustentabilidade ambiental e um segundo grupo discute a diversificação econômica dos municípios mineradores. Desta forma acredita-se que a relação de proximidade do poder público com atividades de pesquisa está presente no Alto Paraopeba.

O quadro 4 sintetiza, a partir da percepção dos entrevistados, qual era a situação da presença das dimensões que compõem o Domínio Recursos Humanos proposto por Isenberg (2011) no ecossistema empreendedor do Alto Paraopeba. Incluindo-se também a situação de relação instituições de ensino e pesquisa-indústria-governo.

\begin{tabular}{|c|c|c|c|}
\hline \multicolumn{4}{|c|}{ Recursos Humanos / Instituições de Ensino e Pesquisa } \\
\hline Dimensões & Presente & $\begin{array}{c}\text { Parcialmente } \\
\text { Presente }\end{array}$ & Não presente \\
\hline $\begin{array}{l}\text { Formação de indivíduos com competências } \\
\text { empreendedoras }\end{array}$ & $\mathrm{x}$ & & \\
\hline Pesquisas & $\mathrm{x}$ & & \\
\hline $\begin{array}{l}\text { Proximidade instituições de ensino e pesquisa- } \\
\text { indústria-governo. }\end{array}$ & & $\mathrm{x}$ & \\
\hline
\end{tabular}

Fonte: Elaborado pelos autores com dados extraídos de entrevistas e análise documental.

\section{CONSIDERAÇÕES FINAIS}

Apesar de ter-se identificado uma relação de trabalho conjunto entre o poder público representado pelo consórcio CODAP com as instituições de ensino e pesquisa federais no fomento do empreendedorismo na região do Alto Paraopeba, foi constatado que existe um desinteresse por muitas prefeituras do território em aderir ao CODAP, comprovado pelo baixo número de prefeituras que são membros do consórcio. Em um total de 15 municípios que compõem a região do Alto Paraopeba, apenas 6 prefeituras faziam parte do CODAP no momento da coleta de dados (CEDEPLAR, 2010; GEOPARK, 2018). E este desinteresse por parte dos municípios em aderir ao CODAP e mantê-lo financeiramente vem enfraquecendo alguns dos objetivos estabelecidos consensualmente para a sua atuação, como, por exemplo, um melhor acompanhamento e gestão dos recursos hídricos ou maior proteção de patrimônio urbanístico, ecológico, paisagístico, cultural e turístico da região, para citar apenas dois que ainda não receberam a devida atenção dos gestores públicos.

A figura 4 retrata o modelo teórico que norteou a elaboração deste trabalho e apresenta a evolução dos elementos que compõem o domínio Políticas Públicas / Poder Público e as dimensões que compõem o domínio Recursos Humanos / Instituições de Ensino. Esses domínios foram escolhidos, nesse estudo, para análise do ecossistema empreendedor do Alto Paraopeba. Os elementos/dimensões que, na nossa avaliação, mais se destacaram em termos de presença e atuação são apresentados por letras maiúsculas, enquanto os que menos apareceram, a partir da investigação, por letras minúsculas. 
Figura 4 - Modelo de análise redesenhado.

\begin{tabular}{|c|c|c|c|c|}
\hline \multicolumn{2}{|c|}{ Políticas Públicas / Poder Público } & \multirow{3}{*}{$\begin{array}{r}\text { Maior } \\
\text { Próximidade }\end{array}$} & $\begin{array}{c}\text { Recursos Humanos / } \\
\text { Instituições de Ensino e }\end{array}$ & \multirow{6}{*}{$\begin{array}{l}\text { Maior possibilidade de } \\
\text { criação de novas empresas } \\
\text { e diversificação econômica } \\
\text { no território }\end{array}$} \\
\hline Liderança & Governo & & $\begin{array}{l}\text { FORMAÇÃO DE } \\
\text { INDIVÍDUOS COM } \\
\text { COMPETÊNCIAS } \\
\text { EMPREENDEDORAS }\end{array}$ & \\
\hline suporte inequívoco & INSTITUIÇÕES DE APOIO & & PESQUISAS & \\
\hline legitimidade social & apoio financeiro & & & \\
\hline $\begin{array}{c}\text { ESTRATÉGIA } \\
\text { EMPREENDEDORA }\end{array}$ & $\begin{array}{l}\text { estrutura regulatória / } \\
\text { legislação facilitadora de } \\
\text { investimentos }\end{array}$ & & & \\
\hline $\begin{array}{c}\text { URGÊNCIA, CRISE } \\
\text { E DESAFIO }\end{array}$ & INSTITUTOS DE PESQUISA & & & \\
\hline
\end{tabular}

Fonte: Elaborado pelos autores a partir da pesquisa de campo

A avaliação é de que o CODAP vem trabalhando para o desenvolvimento e fortalecimento de um ecossistema empreendedor no território do Alto Paraopeba, e que esse ecossistema de negócios fortalecido na região poderá contribuir para a diversificação da economia local, tornando a região menos dependente das atividades relacionadas a mineração e siderurgia. Para que esse processo de planejamento e implantação de ações para fortalecimento econômico e social da região se agilize parece ser necessário haver um alinhamento de interesses entre as prefeituras dos municípios que compõem a região, os representantes do Estado e do governo Federal. Sabendo que a extração do minério de ferro é uma atividade finita e que a região do Alto Paraopeba tem a oportunidade de trabalhar a reconfiguração de sua economia ainda no auge de sua principal atividade econômica, seria oportuno que a gestão dos municípios revisse as disputas partidárias e as desavenças ideológicas que retardam e, muitas vezes inviabilizam planejamento e operacionalização de ações conjuntas e estabelecessem relações cooperativas em prol do desenvolvimento regional.

Apesar desse estudo ter contemplado uma experiência específica - formação do CODAP -, acredita-se que o mesmo traz contribuições tanto para a teoria, quanto para o entendimento do modelo de gestão público de desenvolvimento regional, a partir da constituição de um consórcio público. Para a teoria, acredita-se ter contribuído para ampliar o conhecimento sobre como a manipulação de determinados domínios de um ecossistema empreendedor podem auxiliar na criação de oportunidades empreendedoras em um território. Já para a gestão pública, o estudo pode mostrar que as divergências políticas podem limitar a ação de um consórcio público, ao mesmo tempo permitiu entender como essa estratégia inovadora na gestão pública pode fortalecer as relações de cooperação em prol de ações que visem o desenvolvimento comum e sustentável.

A principal limitação dessa pesquisa foi o fato de não terem sido analisados todos os domínios que compõem um ecossistema empreendedor. Apesar de Isenberg (2011) afirmar que não é necessário que todos os domínios de um ecossistema sofram interferência de uma só vez para redundar em fortalecimento do ambiente de negócios, a análise de todos os domínios poderia proporcionar uma visão mais ampla do contexto empreendedor do Alto Paraopeba. 
A título de futuras pesquisas, sugere-se a realização de estudos similares em outras regiões do país, tomando como referência a discussão sobre ecossistemas empreendedores. O CODAP representa uma iniciativa em construção, o que significa que estudos posteriores que avaliem sua trajetória podem ser interessantes para subsidiar políticas públicas e a adoção de novos consórcios públicos em outros territórios. Sugere-se, por fim, realizar pesquisa que avalie, quantitativamente, os resultados em termos de desenvolvimento para a região, das ações do CODAP e de suas parcerias com os demais atores.

\section{NOTAS}

1 Empreendedorismo autossustentável é aquele que possui a capacidade de se manter ou de se sustentar por seus próprios meios, ou pelo próprio ambiente.

2 Investidor Anjo é uma pessoa física que investe seu próprio capital em empresas nascentes com alto potencial de crescimento (ANJOS DO BRASIL, 2018).

3 Por meio da Lei $n^{\circ} 11.892,2008$ de 29 de dezembro de 2008 foram constituídos os novos Institutos Federais de Educação, Ciência e Tecnologia.

\section{REFERÊNCIAS}

ADNER, R. Match your innovation strategy to your innovation ecosystem. Harvard business review, v. 84, n 4, p. 98, 2006.

ANJOS DO BRASIL. Investidor anjo, 2018. Disponível em:< http://www.anjosdobrasil.net/o-que-eacute-um-investidor-anjo.html >. Acesso em: 08 jul. 2018.

ARIAS, M.; ATIENZA, M.; CADEMARTORI, J. Large mining enterprises and regional development in Chile: between the enclave and cluster. Journal of Economic Geography, v. 14, n. 1, p. 73-95, 2014.

ARRUDA, C.; NOGUEIRA, V. S.; COSTA, V. The Brazilian entrepreneurial ecosystem of startups: An analysis of entrepreneurship determinants in Brazil as seen from the OECD pillars. Journal of Entrepreneurship and Innovation Management, v. 2, n. 3, p. 17-57, 2013.

BARBIERI, A. F.; RUIZ, R. M.; MONTE-MÓR, R. L.; FÍGOLI, M. B.; DOMINGUES, E. P.; RESENDE, M. F; BICALHO, F. W. Plano de desenvolvimento regional para o Alto Paraopeba. Centro de desenvolvimento e planejamento regional - CEDEPLAR, UFMG, 2010.

BORISSENKO, J.; BOSCHMA, R. A critical review of entrepreneurial ecosystems research: towards a future research agenda (No. 2017/3). Lund University, CIRCLE-Center for Innovation, Research and Competences in the Learning Economy, v. 3, 2017.

BYGRAVE, B. Building an entrepreneurial economy: lessons from the United States. Business Strategy Review, v. 9, n. 2, p. 11-18, 1998.

CADEMARTORI, J. El desarrollo económico y social de la Región de Antofagasta (Chile), Historia y perspectiva. Observatorio Regional de Desarrollo Humano (ORDHUM), Ediciones Universitarias, Universidad Católica del Norte, 2009.

CAMILOTTI, L. DE. Procedimentos de integração para o desenvolvimento local a partir dos princípios do empreendedorismo (Dissertação de Mestrado). Universidade Federal de Santa Catarina, Programa de Pós-Graduação em Engenharia de produção, Florianópolis, 2001. 
CARDOSO, F. H.; FALETTO, E. Dependência e desenvolvimento na América Latina. En: Cinquenta anos de pensamento na CEPAL-Rio de Janeiro: Record/CEPAL, v. 2, p. 495$519,2000$.

CARVALHO, L. M. C.; VIANA, A. B. N.; MANTOVANI, D. M. N. O papel da FAPESP no ecossistema empreendedor do Estado de São Paulo. Revista de Administração, Contabilidade e Economia da Fundace, v. 7, n. 1, p. 84-101, 2016.

CODAP. Alto Paraopeba, um dos maiores polos de desenvolvimento do País. Revista CODAP, 2010.2 Disponível em:< http://www.fazitocomunicacao.com.br/imagens/20120311_Rev_CODAP_01.pdf>. Acesso em: 10 ago. 2018.

CRUZ, S. C.; TEIXEIRA, A. A. The evolution of the cluster literature: shedding light on the regional studies-regional science debate. Regional studies, v. 44, n. 9, p. 1263-1288, 2010.

DECRETO-LEI No 11.892, DE 29 DE DEZEMBRO DE 2008. (2008, 29 DE DEZEMBRO). Cria os Institutos Federais de Educação, Ciência e Tecnologia. Brasília. Disponível em <http://www.planalto.gov.br/ccivil_03/_ato2007-2010/2008/lei/111892.htm>. Acesso em: 19 jun. 2018.

ETZKOWITZ, H. Innovation in innovation: The triple helix of university-industrygovernment relations. Social science information, v. 42, n. 3, p. 293-337, 2003.

FOSTER, G.; SHIMIZU, C.; CIESINSKI, S.; DAVILA, A.; HASSAN, S.; JIA, N.; MORRIS, R. Entrepreneurial ecosystems around the globe and company growth dynamics. In World Economic Forum, v.11, 2013.

GEOPARK. Quadrilátero ferrífero. Disponível em:〈http://www.geoparkquadrilatero.org/>. Acesso em: 09 mai. 2018.

GNYAWALI, D. R.; FOGEL, D. S. Environments for entrepreneurship development: key dimensions and research implications. Entrepreneurship theory and practice, v. 18, p. 4362, 1994.

ISENBERG, D. J. How to start an entrepreneurial revolution. Harvard Business Review, v. 88 , n. 6, p. 40-50, 2010.

ISENBERG, D. The entrepreneurship ecosystem strategy as a new paradigm for economic policy: Principles for cultivating entrepreneurship. The Babson Entrepreneurship Ecosystem Project, 2011

KENNEY, M.; PATTON, D. The coevolution of technologies and institutions: Silicon Valley as the iconic high-technology cluster. Cluster genesis: Technology-based industrial development, p. 38-60, 2006.

MARKUSEN, A. Sticky places in slippery space: a typology of industrial districts. Economic geography, v. 72, n. 3, p. 293-313, 1996.

MINAYO, M.; DESLANDES, S.; CRUZ, O.; GOMES, O. Pesquisa Social: teoria, método e criatividade. Vozes, v. 21, 2002.

MINEIRO, A. C.; MIRANDA, B. P.; OTTOBONI, C.; PASIN, L. E. Investigação do potencial de um polo de inovação para a criação de uma rede de investidores anjos a partir de seu ecossistema empreendedor. Revista de Administração, Contabilidade e Economia da Fundace, v. 7, n. 1, p. 71-83, 2016.

ORGANISATION FOR ECONOMIC CO-OPERATION AND DEVELOPMENT. EUROSTAT ENTREPRENEURSHIP INDICATORS PROGRAMME: A COLLECTION OF 
INDICATORS. OECD, 2009, Disponível em:<http://www.insme.org/files/3862>. Acesso em: 20 nov. 2017.

PHELPS, N. A. Cluster or capture? Manufacturing foreign direct investment, external economies and agglomeration. Regional Studies, v. 42, n. 4, p. 457-473, 2008.

PINTO, H.; FERNANDEZ-ESQUINAS, M.; UYARRA, E. Universities and knowledgeintensive business services (KIBS) as sources of knowledge for innovative firms in peripheral regions. Regional Studies, v. 49, n. 11, p. 1873-1891, 2015.

RAMOS, J. Una estrategia de desarrollo a partir de los complejos productivos en torno a los recursos naturales. Revista de la CEPAL, 1998.

REIS, D.; SIMÕES, J. P.; GREATTI, L.; PIZZI, R. F. Empreendedorismo e desenvolvimento local sustentável. Caderno de Administração, v. 14, n. 2, p. 14-24, 2006.

RODRÍGUEZ-CLARE, A. Multinationals, linkages, and economic development. The American Economic Review, v. 86, n. 4, p. 852-873, 1996.

SANTOS, I. C.; PAULA, R. M. A especialização tecnológica local como indutora do empreendedorismo e do desenvolvimento regional: o caso do Vale da Eletrônica brasileiro. Gestão \& Regionalidade, v. 28, n. 82, 2012.

TEECE, D. J. Explicating dynamic capabilities: the nature and microfoundations of (sustainable) enterprise performance. Strategic management journal, v. 28, n. 13, p. 13191350, 2007.

YIN, R. K. Estudo de caso - Planejamento e métodos. Brasil: Bookman, v. 3, 2005. 